JURNAL PATTINGALLOANG

COJurusan Pendidikan Sejarah Fakultas Ilmu Sosial Universitas Negeri Makassar

\title{
Eksistensi Bendung Leko Pancing di Kabupaten Maros 1973-2016
}

\author{
Nurhaidah Yusuf, Muhammad Saleh Madjid, Jumadi \\ Pendidikan Sejarah FIS UNM \\ Nurhaidahyusuf4@gmail.com
}

\begin{abstract}
Abstrak
Tulisan ini membahas mengenai Bendung Leko Pancing di Kabupaten Maros (1973-2016) yang akan terurai dalam beberapa submateri yaitu latar belakang pembangunan Bendung Leko Pancing, perkembangan Bendung Leko Pancing dari awal pembangunan 1973 sampai 2016 dan dampak keberadaan bendung bagi masyarakat. Masalah yang di kaji dalam tulisan ini adalah Bendung Leko Pancing yang berada di Kabupaten Maros yang dibangun di wilayah administrasi Kabupaten Maros tetapi dimanfaatkan sebagai sumber air baku oleh PDAM Makassar melalui Instalasi Pengolahan Air (IPA) II Panaikang untuk memenuhi kebutuhan akan air bersih masyarakat Kota Makassar. Penelitian ini bersifat deskriptif analisis dengan menggunakan metode historis. Melalui tahapan-tahapan, Heuristik dengan menemukan sumber-sumber yang berkaitan dengan penelitian, baik itu berupa buku, brosur maupun mengunjungi lokasi penelitian dan melakukan wawancara yang ada hubungannya dengan penelitian. Dengan melalui kritik, baik itu berupa kritik internal maupun ekstern untuk didapatkan fakta sejarah mengenai Bendung Leko Pancing di Kabupaten Maros. Dari fakta tersebut yang selanjutnya diinterpretasikan secara kronologis kemudian di sajikan dalam suatu tulisan sejarah. Hasil penelitian menunjukkan bahwa Bendung Leko Pancing di Kabupaten Maros pembangunannya dilatarbelakangi atas ketidaktersediaan air permukaan di Kota Makassar yang dapat dimanfaatkan sebagai sumber air baku yang akan diolah sebagai sumber air bersih PDAM Makassar di IPA II Panaikang, serta di Kota Makassar hanya memiliki satu instalasi pengolahan air yaitu Instalasi Pengolahan air I Ratulangi dengan kapasitas 50l/d yang tidak dapat memenuhi kebutuhan akan air bersih masyarakat kota makassar. Dampak keberadaan Bendung Leko pancing yang berada di kabupaten Maros sebagai penyuplai air baku untuk tiga instalasi yang IPA II Panaikang, IPA III Antang dan IPA II Pattontongan telah memberikan manfaat besar sehingga kebutuhan akan air bersih masyarakat bisa tersedia walaupun tidak dapat tersedia sepanjang tahunnya karena ketika musim kemarau pasokan air dari bending menuju instalasi berkurang serta terdapat masalah lain seperti keluhan masyarakat mengenai kualitar air yang kurang bersih dan kadang berbau , dampak lain yang dirasakan masyarakat Karena air dari bendung menuju instalasi menggunakan saluran terbuka maka tidak dpat dihindari adanya penggunaan masyarakat yang memanfaatkan air dari saluran untuk memenuhi kebutuhan sehari-hari.
\end{abstract}

Kata Kunci: Bendung, Leko Pancing.

\begin{abstract}
This Paper discusses Leko Pancing Dam in Maros district (1973-2016) which will be decomposed in several sub-material that is the background of the contruction of Leko Pancing Weir, the development of Leko Pancing Dam from the beginning of the development in
\end{abstract}


1973 until 2016 and the impact of the existence of Weir for the community. The Problem studied in this paper is Leko Pancing Dam located in Maros regency build in Maros District administration area but untilized as raw water source by PDAM Makassar thorough water treatment plant (IPA) Panaikang to fulfill the need of clean water of Makassar City community. The result of research shows that Leko Pancing Dam in Maros Regency development is in the background against the unavailability of surface water in Makassar city which can be used as a sourch of raw water that can be used as if the water source of PDAM Makassar in Panaikang Water Treatment Plant, and in Makassar only has one processing installation water is IPA I Ratulangi with a capacity of 50 liters/second that can not meet the need for clean water Makassar city community. Impact of existence of Leko Pancing Dam which reside in Maros Regency as raw water supply for three water Treatment Plant that is water treatment plant (IPA) II Panaikang, water treatment plant (IPA) III Antang, water treatment plant (IPA) II Pattontongan has benefits so that the need for clean water can be available although it can not be available althoughout the year because during the dry season the water supply from the lute of fishing lute is reducer and other problems such as public complaint that feel the water is less clean and sometimes smelly. Another impact is because water from the weir to the installation uses an open channel then the community uses its water to meet daily needs. This research is descriptive analysis using historis method. Through the stages of heuristics by finding sources related to researce either in the form books, brochures, or visiting the location of research and conduct interviews that have to do with research, the next stage of criticism both in the form of internal criticism and external critism to get historical facts about Leko Pancing weir in Maros district, from these facts which are further interpreted chronologically then presented in a historical writing.

Keyword: Weir, Leko Pancing

\section{A. Pendahuluan}

Air merupakan material yang paling berlimpah di bumi ini, menutupi sekitar 71 persen dari muka bumi. Kehidupan pun hampir seluruhnya air, dimana antara 50 sampai 97 persen dari seluruh berat tanaman dan hewan terdiri dari air dan sekitar 70 persen dari berat tubuh manusia juga terdiri dari air. Manusia dan semua makhluk hidup butuh air karena adanya air, kehidupan bisa terjadi di bumi. (Sujadi, 2008)

Keberadaan air di muka bumi ini sangat melimpah mulai dari mata air, sungai, waduk, danau, laut, hingga samudera. Luas wilayah perairan lebih besar dari pada luas daratan. (Sudarb, 2006) Walaupun demikian tidak seluruhnya dapat dimanfaatkan oleh manusia untuk memenuhi kebutuhan hidupnya seperti kebutuhan akan air bersih dan air minum.
Persyaratan untuk mengelola sumber daya air agar dapat digunakan untuk kepentingan manusia dalam jangka waktu yang panjang terdapat beberapa cara, salah satunya adalah dengan cara membangun fasilitas-fasilitas untukpengendalian aliran air. Fasilitas-fasilitas yang dibangun untuk pengendalian aliran air diantaranya bendung, bendungan, embung dan lain sebagainya. (Triyanto, 2011).

Bendung adalah pembatas yang dibangun melintasi sungai yang akan mengubah karakteristik aliran sungai atau suatu bangunan yang dibuat dari pasangan batu kali, bronjong atau beton, yang terletak melintang pada sungai yang tentu saja bangunan ini dapat digunakan pula untuk kepentingan lain selain irigasi, seperti untuk keperluan air minum, pembangkit listrik atau untuk pengendalian banjir. (Richard Vicky M, dkk. , 2013) 
Di Kabupaten Maros untuk mengendalikan aliran air Sungai Maros agar dapat dipergunakan untuk kebutuhan masyarakat dibangunlah Bendung Leko Pancing yang membentang dialiran Sungai Leko Pancing di Desa Pucak Kecamatan Tompobulu Kabupaten Maros.

Bendung Leko Pancing dibangun pada tahun 1973 pada masa pemerintahan Presiden Soeharto yang disebut Masa Orde Baru dimana pada saat itu sedang berlangsung Program Pemerintah Pembangunan Lima Tahun (PELITA) tepatnya pada Pelita I yang memfokuskan pada memenuhi kebutuhan dasar dan infrastruktur dengan menekankan pada bidang pertanian dan pembangunan Bendung Leko Pancing ini menjadi salah satu infrastruktur yang mendukung program pemerintah tersebut disamping fungsi utama Bendung Leko Pancing sebagai penyumplai air baku untuk diolah sebagai sumber air bersih yang dapat dipergunakan masyarakat untuk memenuhi kebutuhan sehari-hari.

Air yang bersumber dari Bendung Leko Pancing dipergunakan sebagai sumber air baku yang selanjutnya diolah sebagai air bersih. Air baku berarti air bersih yang dipakai untuk keperluan air minum, rumah tangga dan industri Sedangkan Instalasi Pengolahan Air (IPA) atau Water Treatment Plant adalah suatu rangkaian modul peralatan yang bekerja berkesinambungan mengolah air baku menjadi air yang aman dikonsumsi. (Robert J Kodoatie, 2005)

Fungsi utama dari Bendung Leko Pancing ini sebagai sumber air baku yang di kelolah Oleh Perusahaan Daerah Air Minum (PDAM)Kota Makassar dan PDAM Maros dan setelah ketersediaan air untuk air baku tersebut tersedia setelahnya air dari Bendung Leko Pancing didistribusikan untuk irigasi pertanian masyarakat. (Mahmud., 2017)

Mengingat Bendung Leko Pancing berlokasi di Kabupaten Maros tetapi dimanfaatkan oleh PDAM Kota Makassar membuat peneliti tertarik untuk mengkaji secara lebih mendalam Bendung Leko Pancing dimulai dari latar belakang pembangunan pada tahun 1973. Selain itu, peneliti juga tertarik untuk mengkaji perkembangan Bendung Leko Pancing serta dampak keberadaan Bendung Leko Pancing Untuk masyarakat Makassar dan Maros terkhusus Masyarakat sekitar Bendung Leko Pancing.

Penelitian tentang bendung sebelumnya telah ada yang mengkaji yaitu dalam bentuk skripsi tahun 2005 Fakultas Ekonomi Dan Ilmu Sosial, Universitas Negeri Makassar yang ditulis oleh Mujahidah dengan judul Bendung Benteng di Kabupaten Pinrang (1966-1998). Skripsi ini membahas tentang latar belakang pembangunan, perkembangan dan pemanfaatan bendung, kebijakan pemerintah terkait bendung dan organisasi dana tata kerja yang terkait dengan keberadaan bendung.

Karya ilmiah yang lain dalam bentuk skripsi tahun 2001 Fakultas Ilmu Sosial, Universitas Negeri Makassar yang ditulis oleh Abd. Rahman Sejarah Irigasi Sanrego Kecamatan Kahu Kabupaten Bone (19801998). Tulisannya ini membahas tentang latar belakang proses pembangunan irigasi, perkembangan dan pemanfaatan irigasi serta respon masyarakat terhadap keberadaan irigasi di Kabupaten Bone pada umumnya dan Kecamatan Kahu, Desa Sanrego pada khususnya.

Penulisan tentang bendung telah banyak dilakukan oleh peneliti sebelumnya, akan tetapi penelitian tentang Bendung Leko Pancing di Kabupaten Maros yang Fungsi utamanya sebagai penyedia air baku untuk Instalasi pengolahan air dan irigasi belum ada yang teliti sehingga peneliti tertarik meneliti atau mengkaji mengenai Bendung Leko Pancing di Kabupaten Maros.

\section{B. Metode Penelitian}


Penelitian ini menggunakan metode sejarah. Metode sejarah dapat diartikan sebagai cara atau prosedur yang sistematis dalam merekontruksi masa lampau. (Tim Pengajar Pengantar Ilmu Sejarah, 2013)Metode sejarah bertujuan memastikan dan mengatakan kembali fakta masa lampau. Terdapat empat langkah metode sejarah yang wajib hukumnya dilaksanakan oleh sejarawan dalam menulis karya sejarah. Yaitu heuristik, kritik, interpretasi dan historiografi.

\section{Heuristik}

Tahap ini merupakan tahap mencari dan mengumpulkan sumber-sumber sejarah yang terkait dengan topik penelitian. (Tim Pengajar Pengantar Ilmu Sejarah, 2013). Kegiatan diarahkan pada pencarian dan pengumpulan sumber yang berkaitan dengan masalah atau objek yang akan dikaji, yaitu "Bendung Leko Pancing di Kabupaten Maros (1973-2016)". Proses mengumpulkan sumber dalam mengkaji dan menyusun penelitian ini menekankan pada kajian pustaka/library research dan wawancara. Dalam melakukan pengumpulan sumber, menempuh dua cara yaitu penelitian pustaka dan penelitian lapangan.Studi kepustakaan ini dilakukan dengan mengumpulkan sumber melalui berbagai buku-buku, dokumen, arsip, dan laporan penelitian yang berkaitan dengan masalah yang dikaji. sumber pustaka yang penulis peroleh yaitu dari: (1) Kantor desa Pucak Kecamatan Tompobulu Kabupaten Maros (2) arsip Kantor Departemen Pekerjaan Umum Dorektorat Jenderal Sumber Daya Air Balai Besar Wilayah Sungai Pompengan Jeneberang (3) arsip Kantor Satker Operasi \& Pemeliharaan Sumber Daya Air Pompengan Jeneberang (4) arsip perencanaan tata ruang terpadu metropolitan mamminasata dan lain-lain . sedangkan studi lapangan adalah mengumpulkan sumber secara langsung di lapangan terkait dengan judul penelitian, dalam hal ini penulis melakukan penelitian menggunakan dua teknik yaitu observasi dan wawancara.

\section{Kritik}

Kritik terhadap sumber bertujuan untuk memperoleh fakta-fakta yang seobyektif mungkin, sehingga karya sejarah yang dihasilkan merupakan produk dari proses ilmiah yang dapat dipertanggungjawabkan, bukan hasil dari suatu fantasi maupun manipulasi. (Helius Sjamsuddin, 2012).Ketika melakukan kritik sumber, dua hal penting yang harus dilakukan, yakni kritik otentisitas (kritik ekstern) dan kritik kredibilitas (kritik intern). (Tim Pengajar Program Studi Pendidikan Sejarah, 2013)

\section{Interpretasi}

Interpretasi adalah proses pemaknaan sejarah.. Pada tahap interpretasi ini, subyektivitas seorang peneliti akan mulai tampak. Hal ini dapat dipahami karena pada tahap ini imajinasi dibutuhkan untuk menafsirkan seluruh kejadian berdasarkan fakta-fakta sejarah yang telah diperoleh pada tahapan sebelumnya. Terlepas dari hal demikian, peneliti harus bersifat obyektif agar karya yang diperoleh nantinya merupakan karya sejarah yang berkualitas. Fakta-fakta sejarah harus diinterpretasikan atau ditafsirkan agar sesuatu peristiwa dapat direkonstruksikan dengan baik, yakni dengan jalan menyeleksi, menyusun, mengurangi tekanan, dan menempatkan fakta dalam urutan kausal. (Tim Pengajar Pengantar Ilmu Sejarah, 2013)

\section{Historiografi}

Tahap ini merupakan tahap terakhir dalam penelitian sejarah. Pada tahap ini penulis akan menuliskan peristiwa sejarah tersebut dalam sebuah tulisan yang dalam penulisan, pemaparan dan pelaporan menggunakan tata cara tertentu.

\section{Tinjauan Penelitian \\ 1. Keadaan Geografis}

Keadaan geografis adalah segala kondisi yang tersedia oleh alam untukmanusia. 
(Mayor Polak, LB.B, 1970) Khususnya kondisi alam serta meliputi tanah dengan segala keadaan didalamnya. Keadaan geografis suatu masyarakat sebagai objek penelitian sangatlah penting. Mempelajari lokasi berlangsungnya suatu peristiswa merupakan keharusan bagi seorang yang akan mengungkapkan sejarah disuatu daerah. Sebagaimana diungkapkan pula Tamburaka bahwa peranan sejarah ditentukan oleh faktor geografisnya. (Rustam Tamburaka, 1999)Secara administratif Kabupaten Maros memiliki luas wilayah $1.619,12 \mathrm{~km}$ yang kedudukan secara administratif berbatasan dengan :

a. Sebelah Utara berbatasan dengan Kabupaten Pangkep

b. Sebelah Timur berbatasan dengan Kabupaten Bone

c. Sebelah Barat berbatasan dengan Selat Makassar

d. Sebelah Selatan berbatasan dengan Kabupaten Gowa.

Luas wilayah seluruh Kabupaten Maros yaitu $1.619,12 \mathrm{~km}$, kecamatan terluas adalah Kecamatan Tompobulu dengan luas 287,65 $\mathrm{km}$ dengan persentase $17,77 \%$ dari $100 \%$ wilayah Kabupaten Maros, sedangkan kecamatan tersempit yaitu Kecamatan Turikale dengan luas 29,93 km dengan persentase $1,85 \%$ dari keseluruhan wilayah Kabupaten Maros. ( Badan Pusat Statistik Kabupaten Maros, 1990)

\section{Keadaan Demografis}

Berdasarkan hasil survei kependudukan yang ada pada Kantor Badan Pusat Statistik Kabupaten Maros pada tahun 1990, jumlah penduduk di Kabupaten Maros mecapai 239.725. Angka ini terus meningkat dan pada tahun 2010 jumlah penduduk kabupaten maros mencapai 319.002 jiwa . (Badan Pusat Statistik Kabupaten Maros, 2010)

\section{Keadaan Sosial Budaya}

Di Daerah Kabupaten Maros sebagian masyarakat masih menganut sistem norma atau adat istiadat dalam kehidupan sehari- hari. Hal ini diyakini karena akan mempengaruhi kehidupan dimasa mendatang. Misalnya dalam hal mandi tujuh bulanan bagi wanita hamil, kegiatan ini memiliki ciri persamaan yang dilaksanakan oleh setiap daerah, namun hanya namanya yang mungkin berbeda serta alat yang digunakan. (Badan Pusat Statistik Kabupaten Maros, 2010)

\section{Mata Pencaharian}

Pada umunya penduduk yang mendiami wilayah Kabupaten Maros (80\%) bermata pencaharian dibidang pertanian/nelayan dan sisanya adalah sebagai pedagang $(7 \%)$, pegawai negeri $(5 \%)$ buruh dan sebagainya (8\%). Hasil pokok adalah beras, jagung dan ikan serta sebagai hasil tambahan adalah kacang tanah, ubi kayu, beternak kerbau dan unggas (itik, ayam dsbnya). (Departemen Pendidikan Dan Kebudayaan Direktorat Jendral Kebudayaan, 1986)

\section{Pembahasan}

1. Pembangunan Bendung Leko Pancing Bendung Leko Pancing dibangun tepat didaerah aliran Sungai Maros di Desa Pucak Kecamatan Tompobulu Kabupaten Maros. Latar belakang pembangunan Bendung Leko Pancing yang berada di Kabupaten Maros adalah sebagai produsen air baku yang akan dikelola di IPA II Panaikang yang berada di Kota Makassar yang selanjutnya akan dimanfaatkan oleh PDAM Makassar sebagai sumber air bersih masyarakat Kota Makassar.

Dipilihnya Bendung Leko Pancing sebagai sumber air baku dikarenakan Daerah Makassar tidak memiliki sumber air permukaan yang memungkinkan untuk dimanfaatkan sebagai sumber air baku, dan alasan lainnya adalah daerah Kota Makassar sebelumnya hanya memilik satu Instalasi Pengolahan Air yaitu IPA Ratulangi yang berkapasitas produksi $50 \mathrm{l} / \mathrm{d}$ yang tidak memungkinkan bisa memenuhi kebutuhan 
air bersih masyarakat Kota Makassar sehingga dibangunlah IPA II Panaikang sebagai tempat pengolahan air baku menjadi sumber air bersih yang dimana sumber air bakunya berasal dari Bendung Leko Pancing.

Bendung Leko Pancing berada di Kabupaten Maros dominan di manfaatkan oleh masyarakat Kota Makassar hal tersebut bisa terjadi karena Bendung Leko Pancing yang berada di daerah administrasi Kabuputen Maros tidak dikelola oleh Pemerintah Kabupaten Maros sehingga tidak dapat diolah ataupun dimanfaatkan untuk masyarakat Maros.Bendung Leko Pancing milik Pemerintah Pusat yang dikelola oleh Kementrian Pekerjaan Umum Balai Besar Wilayah Sungai Pompengan Jeneberang yang dimanfaatkan oleh Perusahaan Daerah Air Minum (PDAM) Kota Makassar sebagai sumber air baku yang kemudian diolah menjadi sumber air minum sebagian daerah di kota Makassar di Instalasi Pengolahan Air (IPA) II Panaikang.

Bendung Leko Pancing memiliki luas $3.626 \mathrm{Ha}$, hal tersebut yang membuat bendung tersebut dikelolah oleh Pemerintah Pusat. Pembangunan Bendung Leko Pancing yang fungsi utamanya sebagai penyuplai air baku yang kemudian diolah menjadi sumber air minum masyarakat Kota Makassar tidak terlepas dari awal kemerdekaan Indonesia yang hanya bermodalkan kapasitas produksi air minum 3.000 liter per detik yang tersebar di kotakota tertentu yang dulu dihuni orang-orang Belanda. Sarana dan prasarana tersebut adalah peninggalan belanda. (Budiman Arif, 2015) Seperti halnya di Kota Makassar yang dibangun Instalasi pengolahan Air (IPA) I Ratulangi dengan Nama Waterleidjding Bedrïf tahun 1924 dengan kapasitas 50 l/d. (Makassar, LPSE PDAM, n.d.)

Kota Makassar pada awal kemerdekaan hanya memiliki satu Instalasi Pengolahan Air (IPA) yaitu IPA I Ratulangi dengan kapasitas $50 \mathrm{l} / \mathrm{d}$ yang tidak dapat memenuhi kebutuhan air minum untuk masyarakat kota makassar yang pertumbuhan penduduknya semakin meningkat, (Makassar, LPSE PDAM, n.d.)Sehingga melalui proyek pembangunan SPAM skala besar di kota-kota besar/ibukota provinsi tersebut dilaksanakan setelah Jawatan Teknik Penyehatan terbentuk pada akhir tahun 1952. (Budiman Arif, 2015) Salah satu SPAM skala besar yang di bangun ada di Makassar.

Pembangunan SPAM IPA II Panaikang merupakan satu paket pengerjaan dengan Bendung Leko Pancing di Kabupaten Maros karena IPA II Panaikang bisa beroperasi jika ada ada air baku yang bisa diolah dan air baku tersebut berasal dari Bendung Leko Pancing, serta Bendung Leko Pancing dibangun karena adanya pembangunan IPA II Panaikang.

Bendung dibuat dengan tujuan agar permukaan air sungai sekitarnya dapat naik sampai ketinggian tertentu, sehingga air sungai dapat dialirkan kepintu sadap kesaluran keterowongan menuju saluran terbuka yang akan mengalir menuju instalasi pengolahan air sejauh $28,90 \mathrm{~km}$. Karena itu, bendung harus dibuat secara kuat agar tetap bertahan dan kokoh dalam jangka waktu yang lama/panjang. Data teknik Bendung Leko Pancing akan disajikan sebagai berikut : (Pt. Iraya Konsultan , 2007)

1) Bendung Leko Pancing (Bendung Utama)

1.1 Elevasi mercu: el. $+26.30 \mathrm{~m}$

1.2 Lebar mercu : $24.30 \mathrm{~m}$

1.3 Banjur Maksimum Kala Ulang 100 tahunan $(Q$ 100) $=940$ $\mathbf{M}^{3} / \operatorname{det}$

1.4 Debit Rencana Intake : 8.0 $\mathrm{m}^{3} / \mathrm{det}$

1.5 Lebar Pelimpah / pelintasan bambu $=3.0$

1.6 Lebar Intake : 2 × $2.40 \mathrm{~m}$

2) Pintu-pintu Bendung (13 buah) 
JURNAL PATTINGALLOANG

(C)Jurusan Pendidikan Sejarah Fakultas Ilmu Sosial Universitas Negeri Makassar

2.1 Pintu pelintasa bambu : lebar $3.0 \times$ tinggi $1.25 \times 1$ buah

2.2 Pintu intake depan : lebar $2.4 \times$ tinggi $2.5 \times 2$ buah

2.3 Pintu intake hilir : lebar $2.4 \mathrm{x}$ tinggi $1.5 \times 2$ buah

2.4 Pintu penguras intake : lebar $1.0 \times$ tinggi $1.0 \times 2$ buah

2.5 Pintu penguras kantong pasir : lebar $0.5 \times$ tinggi $0.3 \times 3$ buah

2.6 Pintu koker : lebar $1.15 \mathrm{x}$ tinggi $1.5 \times 3$ buah

3) Terowongan dan bangunan penguras

4) Bangunan bagi utama / pelimpah

5) Debit saluran air minum 3.5 $\mathrm{m}^{3} /$ det dan irigasi $\mathrm{Q}=4.5 \mathrm{~m}^{3} / \mathrm{det}$

6) Debit $\mathrm{Q}=2.5 \mathrm{~m}^{3} /$ det, debit minimal air minum tidakk ad air melimpah kesaluran irigasi.

7) Siphon

7.1 Siphon $1: 263,41 \mathrm{~m}$

7.2 Siphon $2: 131,42 \mathrm{~m}$

7.3 Siphon $3: 296,37 \mathrm{~m}$

7.4 Siphon $4: 2.125,53 \mathrm{~m}$

7.5 Siphon $5: 1.863,00 \mathrm{~m}$

7.6 Siphon $6: 413,60 \mathrm{~m}$

7.7 Siphon $7: 180,00 \mathrm{~m}$

8) Lebar bendung kantong pasir : $25,6 \mathrm{~m}$

9) Lebar bendung / intake koker : $180 \mathrm{~m}$ ( tidak termasuk pilar jembatan $7 \times 0.40 \mathrm{~m})$

10) Panjang koker ( intake - outlet koker) : $255 \mathrm{~m}$

11) Palimpah samping sepanjang saluran air baku : 7 buah (untuk memelihara tinggi air saluran)

Dalam proses pembangunan Sungai Maros sebagai lokasi pembangunan Bendung Leko Pancing pada awalnya tidak seluas seperti terlihat sekarang kemudian karena adanya proyek pembangunan Bendung Leko Pancing di aliran Sungai Maros maka sungai tersebut dikeruk dan diperluas. (Sape, 5 April 2018)

\section{Perkembangan Irigasi Bendung Leko Pancing Di Kabupaten Maros (1973- 2016)}

Bendung Leko Pancing di Kabupaten Maros adalah bangunan yang pengerjaannya satu paket dengan pembangunan Instalasi Pengolahan Air (IPA) II Panaikang yang dimana telat ditetapkan bahwa air dari Bendung Leko Pancing akan difungsikan sebagai sumber air baku yang akan diolah menjadi sumber air bersih masyarakat Kota Makassar di IPA II Panaikang.Dalam perkembangan irigasi akan dibagi menjadi dua bagian yaitu perkembangan pada pemanfaatan air dan perkembangan pada bangunan Bendung Leko Pancing.

Dalam perkembangan pemanfaatan air, Pada awal pembangunannya pada tahun 1973 dan mulai beroperasi tahun 1977, air baku dari Bendung Leko Pancing hanya dipergunakan oleh satu Instalasi Pengolahan Air yaitu Instalasi Pengolahan Air II Panaikang tetapi seiring dengan perkembangan waktu pada periode 19731998, air baku dari Bendung Leko Pancing mulai dimanfaatkan oleh Instalasi Pengolahan Air III Antang serta dipergunakan sebagai irigasi. (Arif, 5 Maret 2018)

Pada tahun 1989pemanfaatan air baku dari Bendung Leko Pancing ditingkatkan menjadi 1000 l/d. (Makassar, LPSE PDAM, n.d.)Setelah dua tahun difungsikan sebagai sumber air baku PDAM Kota Makassar tepatnya tahun 1979 , pada saluran terbuka berjarak sekitar $1 \mathrm{~km}$ dari Bendung Leko Pancing dibangun saluran irigasi. (Reski, 7 Maret 2018)

Pada tahun 1985 melalui paket pembangunan Perum Perumnas dibangun IPA III Antang dengan kapasitas awal 20 1/d. Sumber air baku yang dipergunakan di instalasi ini berasal dari air baku Bendung Leko Pancing dengan memanfaatkan saluran terbuka dari Bendung Leko Pancing menuju IPA II Panaikang dan selanjutnya 
menggunakan saluran tertutup sepanjang 2 $\mathrm{km}$ menuju instalasi. (Inventaris Arsip Statis Perusahaan Daerah Air Minum Kotamadya Ujung Pandang Periode Tahun 1922-1985, 1985)Dan pada tahun 1992 dengan bertambahnya pelanggan yang menggunakan air dari IPA II Panaikang untuk memenuhi kebutuhan akan air bersihnya, maka air dari Bendung Leko Pancing pemanfaatannya meningkat dari 20 l/d menjadi 40 l/d. (Makassar, LPSE PDAM, n.d.)

Perkembangan bangunan Bendung Leko Pancing Pada tahun 1980 untuk mengoptimalisasikan sumber air baku yaitu Bendung Leko Pancing untuk ujung pandang (sekarang Makassar) dan sekitarnya maka dibangunlah waduk pengimbang lebih kurang $3.50 \mathrm{~km}$ kearah Hulu dari Bendung Leko Pancing. (Inventaris Arsip Statis Perusahaan Daerah Air Minum Kotamadya Ujung Pandang Periode Tahun 1922-1985, 1985)

Perkembangan Pemanfaatan Air air baku dari Bendung Leko Pancing mengalir menuju IPA II Pattontongan sejauh sekitar 7 $\mathrm{km}$ mulai dimanfaatkan pada tahun 2003 yang saluran nya masih menumpang pada saluran air milik PDAM Makassar dan pada tahun 2007 dibangun satu kolam penjernihan sehingga kapasitas air yang dapat diolah bertambah menjadi 90 (Sahir, 13 Oktober 2017)

Perkembangan Bangunan Bendung Leko PancingSelama kurun waktu 19982016 terdapat bangunan tambahan yang dibangun sebagai bagian dari bendung leko pancing yaitu Bronjong. Bronjong pada Bendung Leko Pancing dibangun pada tahun 2014 guna melindungi dan memperkuat struktur tanah disekitar sungai maros serta sebagai pembentuk Bendung Leko Pancing untuk meningkatkan volume air sungai. Bagian tepi sungai maros sering mengalami erosi akibat arus sungai yang deras dan terus menerus terjadi sehingga pada tahun 2014 ditempatkanlah bronjong sebagai penjaga area tepi sungai dari arus sungai sehingga bantaran sungai tidak mudah hancur.

\section{Dampak Keberadaan Bendung Leko Pancing Bagi Masyarakat}

a. Air Baku

Sumber air baku dan Bendung Leko Pancing termasuk dalam sumber air permukaan walaupun dalam segi kualitas air termasuk dalam kualitas air terburuk dibandingkan dengan sumber air baku lainnya. Namun dalam segi kuantitas dan kontinuitas masih tersedia dalam jumlah yang banyak dari sumber air baku lainnya. Walaupun demikian diperlukan instalasi pengolahan air agar dapat diminum sesuai dengan ketentuan yang berlaku, oleh sebab itu dibangunlah IPA II Panaikang, IPA III Antang dan IPA II Pattontogan yang akan mengolah air baku dari Bnedung Leko Pancing menjadi sumber air bersih.

Dengan adanya bendung Leko Pancing Kebutuhan akan Air bersih sebagian masyarakat Kota Makassar dan Kabupaten Maros btersedia, walaupun dalam sepanjang tahun tidak begitu tercukupi untuk memenuhi kebutuhan sehari-hari dan terdapat masalah lain dalam kualitas air yang dikeluhkan masyarakat yaitu air yang berbau dan dirasa tidak cukup bersih.

\section{a. Sumber Mata Pencaharian}

Terdapat sekelompok masyarakat yang memanfaatkan Bendung Leko Pancing ketika debitnya berkurang tepatnya pada musim kemarau sebagai tempat mengeruk pasir yang selanjunya akan dijual. pasir tersebut banyak bersedimentasi disekitar terowongan bendung. Kegiatan tersebut bisa disebut penambangan pasir.

Penambangan pasir adalah rangkaian kegiatan dalam rangka upaya pencarian, penambangan (penggalian), pengolahan, pemanfaatan dan penjualan bahan galian. Pasir adalah contoh bahan material butiran yang berukuran 0,0625 sampai 2 milimeter. Penambangan pasir bisa di artikan sebagai pengambilan dari dangkal untuk menaikkan 
keatas dengan menggunakan alat atau mesin.Kegiatan penambangan pasir ini terjadi mulai pada tahun 2016 pada saat musim kemarau ataupun ketika air dari hulu sungai maros sedang sedikit .

\section{b. Tempat mencuci, Mandi dan Mencuci Kendaraan.}

Sumber air baku PDAM Kota Makassar dan PDAM Kabupaten Maros yaitu IPA II Panaikang, IPA III Antang dan IPA II Pattontongan melakui saluran terbuka yang mengalir dari Kabupaten Maros melalu Intake sapanjang 28.347 KM adalah jalur terbuka yang mengalir dari titik awal transmisi air baku yaitu Bendung Leko Pancing ketitik akhir disetiap instalasi, dengan menggunakan saluran terbuka tidak dapat dihindari adanya penggunaan air dari Bendung Leko Pancing dari saluran terbuka tersebut oleh masyarakat sepanjang saluran untuk memenuhi kebuhan sehari-hari, pemanfaatan air oleh masyarakat ini tidak dapat dihindari karena saluran menuju Instalasi berada ditengah-tengah pemukiman masyarakat.

\section{E. Kesimpulan}

Bendung Leko Pancing yang berada di Kabupaten Maros dibangun sebagai produsen air baku yang akan diolah di Instalasi Pengolahan Air II Panaikang Kota Makassar. Pemilihan Bendung Leko Pancing dilatarbelakangi oleh Kotam Makassar yang tidak memiliki sumber air permukaan yang dapat diolah menjadi sumber air baku dan Kota Makassar yang hanyak memiliki satu instalasi yang tidak dapat memenuhi kebutuhan akan air bersih masyarakat Kota Makassar.

Dalam periode tahun 1973-2016 Perkembangan Bendung Leko Pancing berkaitan dengan Perkembangan Pemanfaatan Air yaitu air baku dari Bendung Leko Pancing pada awalnya hanya di manfaatkan oleh satu instalasi saja yaitu IPA II Panaikang kemudian seiring dengan perkembangan waktu sampai tahun 2016 telah di manfaatkan oleh tiga instalasi yaitu IPA II Panaikang, IPA III Antang dan IPA II Pattontongan. kemudian dalam hal perkembangan bangunan bendung dimana dibangun bangunan baru berupa pembangunan bendung pengimbang, terowongan serta dilakukan rehabilitasi pada bagian bendung dan saluran terbuka yang mengalami kerusakan.

Keberadaan Bendung Leko Pancing di Kabupaten Maros menimbulkan perubahan sosial bagi masyarakat Kota Makassar dan Kabupaten Maros dalam hal penggunaan air. Dengan adanya Bendung Leko Pancing, masyarakat baik yang berada di sekitar bendung maupun disekitar aliran air menuju instalasi menerima dampak yang dimana masyarakat memanfaatkan air dari Bendung Leko Pancing untuk memenuhi kebutuhan akan air bersih yang walaupun ketersediaannya tidak sepanjang tahun serta masyarakat memanfaatkannya sebagai sumber mata pencaharian dan memenuhi kebutuhan sehari-hari masyarakat yang bertempat tinggal di sepanjang saluran terbuka menuji instalasi.

\section{DAFTAR PUSTAKA}

Badan Pusat Statistik Kabupaten Maros, 1990. Maros dalam Angka 1990, Indonesia: s.n.

Arif, S., 5 Maret 2018. PDAM Makassar [Interview] (5 maret 5 Maret 2018).

Badan Pusat Statistik Kabupaten Maros, 2010. Maros dalam Angka 2010, Indonesia: s.n.

Budiman Arif, 2015. Pengembangan Air Minum Indonesia Dari Masa Kemasa 1800an-2009. Indonesia: Kementerian Pekerjaan Umum Dan Perumahan Rakyat.

Budiman Arif, 2015. Pengembangan Air Minum Indonesia Dari Masa Kemasa 
1800an-2009. Indonesia: Kementerian

Pekerjaan Umum dan Perumahan Rakyat.

Departemen Pendidikan Dan Kebudayaan Direktorat Jendral Kebudayaan, 1986.

Laporan Pengumpulan Data Peninggalan Sejarah Purbakala Di Kabupaten Maros, Indonesia: Suaka Peninggalan Sejarah Dan Purbakala Sulawesi Selatan..

Eka Sudarb, 2006. Buku Pelajaran SMA: Geografi. Jakarta: Erlangga. Pp. 45. Jakarta: Erlangga.

Firman sujadi ST, 2008. Air Bersih Sumber Kehidupan Sehat. Bandung: shakti adiluhung.

Firman sujadi ST, 2008. Air Bersih Sumber Kehidupan Sehat. Bandung: Shakti Adiluhung, pp. 6. Bandung: shakti adiluhung.

Helius Sjamsuddin, 2012. Metodologi Sejarah. Indonesia(Yokyakarta): Ombak.

Inventaris Arsip Statis Perusahaan Daerah Air Minum Kotamadya Ujung Pandang Periode Tahun 1922-1985, 1985. No. Reg. 1674 . Surat Pemecahan Masalah Air Baku Perusahaan Daerah Air Minum Kotamadya Ujung Pandang, Indonesia: PDAM Makassar.

Inventaris Arsip Statis Perusahaan Daerah Air Minum Kotamadya Ujung Pandang Periode Tahun 1922-1985, 1985. PDAM Makassar, Indonesia: PDAM Makassar.

Mahmud., 2017. fungsi utama pembanguna bendung leko pancing [Interview] (13 oktober 2017).
Mahmud, 2017. Fungsi Utama Pembanguna Bendung Leko Pancing [Interview] (18 Oktober 2017).

Makassar, LPSE PDAM, n.d. sejarah PDAM Makassar. [Online] Available at: Http://PdamMakassar.Com/?P=534 Diakses 8 Maret 2018. [Accessed 8 maret 2018].

Mayor Polak, LB.B, 1970. Sosiologi Suatu Pengantar Ringkasan. Indonesia: Ikhtisan.

Pt. Iraya Konsultan , 2007. Laporan Akhir (Final Report) Ku.08.08/PpkPp/17/Vi/2007 Tanggal 13 Juni 2007 Pekerjaan Detail Desain Saluran Air Baku Lekopancing Kab, Maros Dan Kota Makassar, Indonesia: Departemen Pekerjaan Umum Direktorat Jenderal Sumber Daya Air Balai Besar Wilayah Sungai Pompengan Jeneberang..

Reski, H., 7 Maret 2018. Bendung Leko Pancing [Interview] (7 Maret 7 Maret 2018).

Richard Vicky M, dkk. , 2013. Perencanaan Bendung Untuk Daerah Irigasi Sulu. p. 16.

Robert J Kodoatie, Ph. H., 2005. Pengelolaan Sumber Daya air terpadu. Yokyakarta: Andi.

Rustam Tamburaka, 1999. Pengantar Ilmu Sejarah, Teori Filsafat Sejarah, Sejarah Filsafat Dan Iptek. Indonesia: Rineka Cipta.

Sahir, 13 Oktober 2017. Sejarah IPA II Pattontongan [Interview] (13 Oktober 13 Oktober 2017).

Sape, H., 5 April 2018. proses pembangunan Bendung Leko Pancing [Interview] (5 april 5 April 2018). 
Sejarah, T. P. J. P., 2014. Pengantar Ilmu Sejarah. (Makassar: Universitas Negeri Makassar, 2013), Hal. 31. Makassar: UNM.

Sudarb, E., 2006. Buku Pelajaran SMA: Geografi.. jakarta: erlangga.

Tim Pengajar Pengantar Ilmu Sejarah, 2013. Pengantar Ilmu Sejarah. Makassar: Fakultas Ilmu Sosial.

Tim Pengajar Program Studi Pendidikan Sejarah, 2013. Pengantar Ilmu Sejarah. Indonesia(Sulawesi Selatan): s.n.

Triyanto, 2011. Analisis desain bendungan Bribin II kabupaten gunung kidul yokyakarta, Indonesia: s.n.

Triyanto, 2011. Analisis desain bendungan Bribin II kabupaten gunung kidul yokyakarta. p. 1. 